\title{
Erratum to: Advanced in Optical Network Control and Management
}

\author{
Mahmoud Daneshmand • Chonggang Wang • \\ Wei Wei · Keping Long
}

Published online: 13 January 2012

(C) Springer Science+Business Media, LLC 2012

\section{Erratum to: J Netw Syst Manage \\ DOI 10.1007/s10922-011-9222-0}

The publisher regrets that the title and the guest editor's name in "Advanced in Optical Network Control and Management" (DOI 10.1007/s10922-011-9222-0) have been misspelled. The correct spelling of the title is "Advances in Optical Networks Control and Management" and the correct spelling of the guest editor's name is "Mahmoud Daneshmand".

The online version of the original article can be found under doi:10.1007/s10922-011-9222-0.

\author{
M. Daneshmand \\ Middledown, NJ, USA \\ e-mail: daneshmand@research.att.com \\ C. Wang $(\bowtie)$ \\ King of Prussia, USA \\ e-mail: cgwang@ieee.org \\ W. Wei \\ Dallas, TX, USA \\ e-mail: wwei@ieee.org \\ K. Long \\ Beijing, China \\ e-mail: longkeping@ustb.edu.cn
}

